\title{
Cultural Diversity and Organizational Commitment: A Study on Teachers of Primary Public Schools in Menoufia (Egypt)
}

\author{
Mohamed Mousa ${ }^{1}$, Ruth Alas ${ }^{1}$ \\ ${ }^{1}$ Estonian Business School, Estonia, Europe \\ Correspondence: Mohamed Mousa, Estonian Business School, Estonia. E-mail: Mohamed.mousa@ebs.ee
}

Received: May 11, 2016

Accepted: May 26, $2016 \quad$ Online Published: June 14, 2016

doi:10.5539/ibr.v9n7p154

URL: http://dx.doi.org/10.5539/ibr.v9n7p154

\begin{abstract}
With globalization and mounting global uncertainties, cultural diversity has become one of the main factors affecting both in-and-out life of any organization. Hence, responding to cultural diversity is a challenging organizational priority in order to achieve organizational goals. It entails absorbing differences and creating a healthy environment in which all employees feel valued, and their talents are fully utilized. During the last three decades, organizational commitment has gained popularity by examining employees' link to their organization. It has a tremendous role in shaping the future of organizational orientation. This study explores the link between cultural diversity challenges and organizational commitment approaches by conducting a quantitative study of teachers in a public primary school in Menoufia province (Egypt). Both correlation and regression analysis of collected data indicate that it is true to assume that not all challenges of cultural diversity have a positive effect on organizational commitment approaches.
\end{abstract}

Keywords: cultural diversity, communication, discrimination, training, organizational commitment, Egypt

\section{Introduction}

The concern for cultural diversity has been widely accepted as an effective business issue, and it sets a new framework for people management practices in the 21st century (Subeliani \& Tsogas, 2005). Reportedly, initial efforts to address cultural diversity focused mainly on gender and race (Morrison, Lumby \& Sood, 2006).

In addition to political, social, educational, and economic challenges, globalization has led to a development in cultural competences and to a world that is increasingly diverse (Pitts \& Wise, 2010). Consequently, cultural diversity has broadly expanded to include gender, race, religion, ethnicity, sexual orientation, physical ability, income, work experience, marital status, educational background and other differences that may affect the workplace (Heuberger, Gerber \& Anderson, 2010).

Responding to cultural diversity is one of the main challenges facing any organization. It entails absorbing differences and creating a productive environment in which employees feel valued while their talents are utilized for the attainment of organizational goals (Findler, Wind \& Berak, 2007). Moreover, Kormanik and Rajan (2010) explain that managing diversity means becoming aware of behaviors, acknowledging biases, and focusing on job codes of conduct. Indeed, cultural diversity is no longer limited to management intervention or affirmative action, but it can be employed as a strength to accomplish organizational missions (Pitts and Wise, 2010). Accordingly, developing human resources knowledge about the potential benefits that differences can bring to the workplace is an emergent organizational practice (Vuuren, Westhuizen\& Walt, 2012). Therefore, many universities have started to pursue well thought-out strategies of developing their human resources to accept, respect, tolerate and appreciate others as a kind of alignment with global trends (Heuberger et al, 2010).

In a different perspective, organizational commitment has become a keystone in both management and behavioral science over the last 30 years (Rajendran \& Raduan, 2005). Many studies (Chang, 1999; Clercq \& Rius, 2007; Kaur \& Sharma, 2015 and Mousa \& Alas, 2016) affirm its importance in examining the state of employees' organizational membership and subsequently in forecasting the future of this membership. Additionally, Chang (1999); Haim (2007); Sharma \& Sinha (2015); and Alas \& Mousa (2016) maintain that organizational commitment provides an explanation for employees' misuse of power, irresponsibility, inefficiency and carelessness in work. Moreover, it often interprets employees' modes of behavior in face of organizational crisis (Chang, 2002). Allen and Meyer (1990) have classified organizational commitment into three approaches: affective, continuance, and normative, which will be illustrated later in detail. 
Education is often seen as a paradigm on which developing nations rely to accelerate their potential growth (Alzaroo \& Hunt, 2003). Egypt is one of the developing nations that have tried to use education as a mechanism for attaining economic soundness and organizational effectiveness (Mahrous \& Kortam, 2012). Egypt is currently facing a serious problem that affects the whole educational process; the majority of its teachers are leaving their jobs in governmental schools in search for better work opportunities in the private sector and gulf countries.

Many teachers claim that besides their low salaries, they are afraid of the changes of their job roles, responsibilities and promotion opportunities. Others claim that they suffer from the continuous changes in their leadership and subsequently functions within their work units. Since governmental schools are the main destination for Egyptian children of low and middle income families, this lack of teachers' commitment may harm not only the whole educational process but also the intended economic reform.

Considering the above and the limited research conducted to investigate the association between cultural diversity and organizational commitment of Egyptian teachers, this study seeks to fill in this gap by examining such association in public primary schools in Menoufia, Egypt.

\section{Literature Review}

\subsection{Cultural Diversity}

Research about cultural diversity started in the USA in 1970 by investigating positions of socio-demographic groups and the inequality derived from racio-ethnic lines and gender (Zanoni et al., 2009). The first studies about cultural diversity aimed at understanding how gender and race constitute the main factors of conflict inside each organization (Dogra, 2001) and subsequently what constraints faced ethnic minorities and women in the workplace.

Before examining the meaning of cultural diversity, it is important to identify in more specific terms the meaning of culture and diversity. Culture means "the collective programming of the mind that distinguishes the members of one group or category of people from another" (Hofstede and Hofstede, 2005, p.28). The concept 'diversity' refers to "the state of being different or varied. The term is derived from the root "divers" or "diverse" which in turn is derived from the Latin diversus, meaning: turned in different directions" (Sinclair, 1999 according to Vuuren et al., 2012).

According to Vuuren et al. (2012, p. 156) cultural diversity is "the differences in ethnicity, background, historical origins, religion, socio-economic status, personality, disposition, nature and many more". Moreover, Heuberger, Gerber and Andersson (2010, p.107) defined it as "many types of differences, such as racial, ethnic, religious, gender, sexual orientation, and physical ability, among others". The concept of cultural diversity has been referred to as "a source of sustained competitive advantage derived from a large pool of resources, ideas, opinions, values, resulting in a broader range of task-related knowledge, abilities and skills than homogeneous ones" (Zanoni et al, 2009, p. 11).

Although the discourse on cultural diversity started in the USA by focusing on differences in ethnicity and gender, it now goes beyond this narrow range to include differences among individuals (tall, short, thin, bald, blonde, intelligent, physically or mentally disabled, and so on) and differences among subgroups in terms of age, sexual preferences, socio-economic status, religious affiliation, language, and so on (Vuuren et al, 2012). That's why Humphrey, Bartolo, Alc, Calleja, Hofsaess, Janikofa, Lous, Vilkeine \& Westo (2006) consider any society as constituting a diverse range of groups that have diverse needs.

Concerning the benefits of cultural diversity, Ogbonna and Harris (2006) indicate that with a positive appraisal of cultural diversity, firms may decide to recruit diverse international workforces in order to have better access to and understanding of different markets. It is a case of broadening business range by consciously selecting a wider variety of diverse personal qualities in order to attain competitive success. Roberson and Park (2007) consider that a multicultural workforce results in productivity and competitive benefit. In addition, working in/with a multicultural workforce helps in attracting and retaining talents. This helps in reducing absenteeism and turnover. Moreover, Humphrey et al. (2006) stress that educating people to appreciate cultural diversity entails a support for the values of inclusion and solidarity. Countries can't mirror any democratic norms without promoting respect for diversity and its corresponding values of freedom, equality, and tolerance.

In order to demonstrate commitment to cultural diversity, organizations adequately address both tacit and explicit knowledge (e.g. making a business case for diversity, providing opportunities for intergroup contact, and adopting culturally relevant concepts through experimental learning) in their practices (King, Gulick \& Avery, 2010). That is why academic scholars advocate that meeting personal, organizational, and social needs for cultural diversity requires tailoring initiatives (training, coaching, workshops, mentoring, and special courses) to develop a kind of awareness of cultural diversity (Roberson, Kulik, \& Pepper, 2001). Accordingly, many educational and business organizations have changed their orientation from seeing cultural diversity training as a one-time seminar experience to a continuous training program taken at regular intervals (e.g. monthly) (Misra and McMahon, 2006). Additionally, many 
organizations have started to integrate cultural diversity aspects into other training fields, including sales training, communication training, and leadership training. This would foster employee engagement into multiple cultural diversity training programs during their careers (Roberson et al, 2001). According to Devine, Baum, Hearns and Devine (2007), for effective management of cultural diversity, organizations should overcome the following three main challenges: First, communication challenges which reflect the lack of knowledge and uncertainty of how people who are different receive and interpret behaviors of others. Abidin et al (2010) indicate that the importance of communication derives from employees' need to know what is expected from them, how to implement what is expected from them, and how to respond to the expected feedback. Second, the discrimination challenge reflects unjustified intentional negative actions towards members of a group simply because of their membership in this group (Ogbonna \& Harris, 2006). Third, the training challenge means responding to legal and social pressure, remaining competitive in a marketplace, and adapting with tolerant moral standards by designing programs for enhancing employees' awareness and acceptance of others (Wentling \& Rivas, 1999 and King, Gulick \& Avery, 2010).

\section{Organizational Commitment}

Even though the concept "organizational commitment" has appeared in the early 1970s to assess employees' affective attachment towards their employer, the concept has evolved to discuss employees' behaviors within their organizations and subsequently to occupy a noticeable space in management academic discourse (Clercq \& Rius, 2007; Kaur \& Sharma, 2015).

Organizational commitment has been defined by Porter et al. (1974) as "an acceptance of the organizational goals, willingness to put the maximum effort on part of the organization, and a desire to maintain membership in the organization". Mowday, Porter and Stears (1982) consider it as "The extent to which an individual identifies and involved with his or her organization and/or is unwilling to leave it". It also represents "a psychological state that characterizes an employee's relationship with the organization and reduces the likelihood that he/she will leave it" (Allen \& Meyer, 2000). Moreover, Gbadamosi (2003) considers it as "identification, involvement and loyalty as well as a feeling of obligation to stay with one's organization", whereas, Haim (2007) states that organizational commitment is "a rational behavior of employees, designed to protect their occupational and employment assets in terms of salary and benefits, and as a function of tenure". In their seminal research article, Allen and Meyer (1990) have classified organizational commitment into three approaches: affective, continuance and normative.

\subsection{Affective commitment}

This refers to an employee's emotional attachment to, integration with, and involvement with his organization (Bryant et al., 2007). Enriquez et al. (2001) elaborate that organizational objectives, vision, and level of freedom employees enjoy are three determinants for the level of employees' affective commitment. Perry (2004) points out that promoting healthy, friendly and supportive discussions with supervisors may positively affect the level of employees' affective commitment.

\subsection{Continuance commitment}

This refers to an employee's perceived costs of leaving his organization (Bryant et al, 2007). Becker (1960) indicates that employees invest time, effort, health, money, and so on in their organizations. Such investments strongly affect their decisions and/or intentions to leave or remain in their organizations. Accordingly, Sharma \& Sinha (2015) maintain that an increase in employees' age and tenure within organizations raises their perceived cost of leaving it. Employees may also think about their pension, knowledge, job security, and unused vacations upon considering the decision to leave their jobs (Sharma \& Sinha, 2015).

\subsection{Normative Commitment}

This reflects an employee's obligation to stay in his or her organization (Bryant et al, 2007). Organizational culture, rewards, punishments, and employee autonomy play a vital role in deciding the level of normative commitment (Meyer \& Allen, 1997; Chang, 2002; Haar \& Spell, 2004, and Sharma \& Sinha, 2015).

Due to the importance of organizational commitment, many studies (Mowday et al., 1982; Meyer \& Allen, 1997; Chang, 1999; Allen \& Meyer, 2000; Chang, 2002; Abidin et al., 2010 and Mousa \& Alas, 2016) have focused on discussing and investigating its context (definition, approaches and consequences). Furthermore, Li, Ahlstrom, and Ashkanasy (2010) highlight that the importance of organizational commitment is derived from its strong impact on organizational performance and subsequently, organizational success. Abidin, Muda, Hasan and Salleh (2010) claim that employees who identify with their organization tend to focus much more on their organizational survival and competiveness. That explains why they do their best to attain better quality work performance and to fulfill their responsibilities in achieving higher productivity rates. Moreover, Omar, Anuar, Majid and Johari (2012) highlight that committed employees are the most valuable assets for any organization. Thus, having committed employees enhances organizational competitiveness 
by reducing rates of turnover and intentions to quit (Omar et al, 2012).

From a different perspective, Haim (2007) raises the argument of whether or not organizations should keep their long-term commitment to their workplace despite the on-going technologization and globalization. He indicates that there is a growing trend towards downsizing and outsourcing of labor activities which may yield a need to restructure the meaning and measurement of the concept of 'organizational commitment'.

\subsection{Egypt and Cultural Diversity}

The Arab Republic of Egypt, also known as "Misr" or "Egypt", is the country that has the largest population in the Middle East and the Arab region. Egypt is situated in the eastern part of North Africa. It occupies a strategic location owing to the Suez Canal, a vital waterway for the world's commodities especially oil. This country stretches from the border with Libya in the west to the Gaza strip in the east. Due to its history, location, population, culture, and military power, Egypt is perceived by the world as a leader in the Arab region.

Based on the OECD 2008 report, Egypt experienced a significant economic growth from the year 2000 to the year 2008. As the economic performance of the country was ambitious in financial and industrial fronts, the country attracted many European and multinational companies to invest and run businesses such as Vodafone, City Bank, HSBC bank, and others. Furthermore, it attracted many hundreds of foreign industrial investors to invest in small and medium-sized enterprises there. The caliber and performance of the foreign employees in these companies surpassed that of Egyptian employees, and this created more competition in the labor market.

Given the previous, a change in mentalities of the Egyptian workforce has occurred. Local citizens are now more eager to improve their skills to be able to join the workforce in private and foreign companies and banks. These companies, especially the European ones, have started to recruit Egyptian graduates with some professional and foreign educational certificates; such as a Masters of Business Administration, Masters of Science, or International certificates in finance. Moreover, English has become the main language of communication inside private companies. Proficiency in English is perceived as a basic requirement in any job description.

There is no doubt that political stability was the main factor in this notable economic development during the years 2000 to 2008. However, the existing political stability at that time does not mean that there were no challenges. Absence of freedom, low quality education, unequal distribution of wealth, inadequate infrastructure, poor services, and violations of human rights were the phenomena distinguishing this country all through the first decade of the $21^{\text {st }}$ century (Bauer, 2013). All these factors instigated the need to revolt against the deteriorating state of the country.

In 2011, Egypt witnessed a revolution with the aim of overthrowing its dictator president to attain political, cultural and social freedom; however, there have not been any significant changes in the political, economic and social justices up till now. Since this time, strikes and protests have constituted undisputed facets of Egyptians' daily lives; many religious and cultural groups such as Christians, Muslim Shia, and Baha'is have been calling for their religious rights (Stel, 2013). Local workers have been demanding a discernable increase in their wages. Women and youth are seeking empowerment. Consequently, some have recorded an escalating rate of violent events in most major cities in Egypt. And religious scholars have started to instruct Egyptian citizens to accept each other and to respect their differences. This harsh environment is an ideal climate for disseminating the values "cultural diversity" and commitment.

\section{Research Methodology}

\subsection{Conceptual Framework}

The conceptual framework of this study is designed based on a review of previous studies that have been conducted to demonstrate the relationship between cultural diversity and organizational commitment. In this study, the proposed independent variables are: communication, discrimination and training. Organizational commitment approaches (affective, continuance and normative) function as dependent variables.

\subsection{Hypotheses}

Based on the previous literature review, the researcher will test the following hypotheses:

- H1: not all cultural diversity challenges (communication, discrimination and training) have a positive relationship with affective commitment.

- H2: not all cultural diversity challenges (communication, discrimination and training) have a positive relationship with normative commitment.

- H3: not all cultural diversity challenges (communication, discrimination and training) have a positive relationship with continuance commitment. 


\subsection{Survey Instruments}

This quantitative research uses a questionnaire to collect primary data. Most questions included in the questionnaire are based on established, existing models, with some modifications made to the original questions with regards to the cultural aspect of this study sample. The questionnaire prepared for this study contains three main sections: Demographic variables, organizational commitment and cultural diversity. A five-point Likert scale is used for all items under organizational commitment and cultural diversity.

- Section A: Demographic Variables: Involve questions about the personal information of the targeted respondents such as gender, age, marital status, level of income and organizational tenure.

- Section B: Organizational Commitment: is based on Allen and Mayer's (1990) three dimensional model of organizational commitment. This covers the three approaches of organizational commitment: affective, continuance and normative. This section also includes three subscales, and each subscale has eight items.

- Section C: cultural diversity: Given the three components of cultural diversity suggested by Devine et al. (2007), the researchers of this study have prepared this section to cover three selected challenges of cultural diversity: communication, discrimination and training. This section includes three subscales, the first subscale involves five questions about communication, and the second has six questions about discrimination, and the third contains four questions about training.

\subsection{Scope of the Study}

Teachers who are working in public schools in Menoufia Province, Egypt are the main population sample of this study. They are chosen as a sample for this study because they represent the category of Egyptian teachers who are working in public schools and who are likely to opt for offers from private schools or to accept others from Gulf countries. Also, it deserves to be mentioned that the researcher was able to reach many teachers in this province.

By dividing the population into homogenous subgroups and then taking a simple random sample from each subgroup, the researcher relies on stratified random sampling in order to reduce any possible bias and at the same time ensure that the chosen simple random sample represents the general population.

Since teachers who are working in Egyptian public schools are classified into five categories: junior teachers, first class teachers, alpha first class teachers, expert teachers and senior teachers, the use of stratified random sampling guarantees that each subgroup is represented in the chosen sample. And because it is difficult to determine the size of population in this case, the researcher has chosen to distribute 200 sets of questionnaires to the targeted respondents. Needless to say, the sets of questionnaire will be delivered in both Arabic and English to match the abilities of all targeted respondents and to motivate them to respond.

\subsection{Data Analysis}

For data analysis, the SPSS was used to obtain descriptive statistics of frequency distributions, means, and standard deviations. The SPSS Pearson correlation was adopted to enable hypotheses testing.

\section{Research Findings}

As previously stated, the researchers distributed 200 sets of questionnaires and received responses from 150 teachers. With the help of stratified random sampling, the researchers formed the following profiles for respondents (see Table 1) 
Table 1. Demographics

\begin{tabular}{|c|c|c|}
\hline Demographic Variables & Items & Count \\
\hline \multirow[t]{2}{*}{ Gender } & Male & 123 \\
\hline & Female & 27 \\
\hline \multirow[t]{7}{*}{ Age } & below 25 years & 15 \\
\hline & $26-30$ years & 30 \\
\hline & $31-35$ years & 30 \\
\hline & $36-40$ years & 25 \\
\hline & $41-45$ years & 20 \\
\hline & $46-50$ years & 20 \\
\hline & More than 50 years & 10 \\
\hline \multirow[t]{3}{*}{ Marital Status } & Single & 40 \\
\hline & Married & 74 \\
\hline & Other & 36 \\
\hline \multirow[t]{3}{*}{ Level of Education } & Bachelor & 100 \\
\hline & Bachelor + Diploma & 48 \\
\hline & Master & 2 \\
\hline \multirow[t]{5}{*}{ Level of Income } & EGP 1200 & 15 \\
\hline & EGP $1300-2500$ & 60 \\
\hline & EGP 2500-4000 & 65 \\
\hline & EGP 4000-5500 & 10 \\
\hline & Above 5500 & 0 \\
\hline \multirow[t]{6}{*}{ Organizational tenure } & Less than 1 year & 0 \\
\hline & 1-3 years & 45 \\
\hline & 4-6 years & 55 \\
\hline & $7-9$ years & 40 \\
\hline & $10-12$ years & 10 \\
\hline & Above 15 years & 0 \\
\hline \multirow[t]{2}{*}{ Religion } & Muslim & 145 \\
\hline & Christian & 5 \\
\hline \multirow[t]{2}{*}{ Work Bases } & Full time & 150 \\
\hline & Part time & 0 \\
\hline
\end{tabular}

Reliability Analysis

The Cronbach alpha is used to assess the internal consistency of each of the variables used in the study. As depicted in Table 1, all variables have adequate levels of internal consistency, and they meet the acceptable standard of 0.60 (Sekaran, 2003). In this study, the Cronbach Alpha Coefficient is 0.907 (see Table 2).

Table 2. Reliability Analysis

\begin{tabular}{lll}
\hline Scale name & Number of items & Coefficient alpha values \\
\hline Organizational Commitment & 24 & 0.904 \\
Affective commitment & 8 & 0.771 \\
Continuance commitment & 8 & 0.760 \\
Normative commitment & 8 & 0.801 \\
Cultural diversity & 15 & 0.707 \\
Communication & 5 & 0.804 \\
Discrimination & 6 & 0.745 \\
Training & 4 & 0.715 \\
Total & 39 & 0.907 \\
\hline
\end{tabular}

\section{Hypothesis 1}

a) The analysis results in a Pearson coefficient of 0.695 , and this value is highly significant $(\mathrm{P}=0.0)$. This positive correction coefficient proves that communication positively affects teachers' affective commitment. The result (R2= $0.483, \mathrm{P}=0.0$ ) suggests that when communication is assigned, there is a $48.3 \%$ increase in teachers' affective commitment (see Table 3).

Table 3. Correlation and Regression between Communication and Affective Commitment

\begin{tabular}{lllll}
\hline Model & $\mathrm{R}$ & $\mathrm{R}^{2}$ & Adjusted $\mathrm{R}^{2}$ & SE of the estimate \\
\hline 1 & .695 & .483 & .479 & .367 \\
\hline
\end{tabular}

b) The analysis results in a Pearson coefficient of -0.398 , and the value is highly significant $(\mathrm{P}=0.0)$. This negative correlation coefficient proves that discrimination negatively affects teachers' affective commitment. The result $(\mathrm{R} 2=$ $0.159, \mathrm{P}=0.0$ ) suggests that if teachers feel discrimination, the result is a $15.9 \%$ decrease in affective commitment (see Table 4). 
Table 4. Correlation and Regression between Discrimination and Affective Commitment

\begin{tabular}{|c|c|c|c|c|}
\hline Model & $\mathrm{R}$ & $\mathrm{R}^{2}$ & Adjusted $\mathrm{R}^{2}$ & $\begin{array}{l}\mathrm{SE} \text { of the } \\
\text { estimate }\end{array}$ \\
\hline 1 & -.398 & .159 & .153 & .468 \\
\hline
\end{tabular}

c) The analysis results in a Pearson coefficient of 0.745 , and the value is highly significant $(\mathrm{P}=0.00)$. This positive correction coefficient proves that training positively affects teachers' affective commitment. The result $(\mathrm{R} 2=0.555$, $\mathrm{P}=$ 0.0 ) suggests that when training exists, there is a $55.5 \%$ increase in teachers' affective commitment (see Table 5).

Table 5. Correlation and Regression between Affective Commitment and Organizational Values

\begin{tabular}{lllll}
\hline Model & $\mathrm{R}$ & $\mathrm{R}^{2}$ & Adjusted $\mathrm{R}^{2}$ & $\begin{array}{c}\text { SE } \\
\text { estimate }\end{array}$ \\
\hline 1 & .745 & .555 & .552 & .340 \\
\hline
\end{tabular}

Findings 1: Since both communication and training positively affect affective commitment whereas discrimination negatively affects it, the first hypothesis is fully supported. The results show that training (.555) has much more effect than communication $(0.483)$ on the level of affective commitment.

\section{Hypothesis 2}

a) The analysis results in a Pearson coefficient of 0.634 , and the value is highly significant $(\mathrm{P}=0.0)$. This result indicates that communication positively affects continuance commitment. The result $(\mathrm{R} 2=0.402, \mathrm{P}=0.0)$ suggests that when communication is well-utilized, there is a $40.2 \%$ increase in teachers' continuance commitment (see table 6).

Table 6. Correlation and Regression between Continuance Commitment and Meaningful Work

\begin{tabular}{lllll}
\hline Model & $\mathrm{r}$ & $\mathrm{R}^{2}$ & Adjusted $\mathrm{R}^{2}$ & SE of the estimate \\
\hline 1 & .634 & .402 & .398 & .422
\end{tabular}

b) The analysis results in a Pearson coefficient of -0.369 , and the value is highly significant $(\mathrm{P}=0.0)$. This result proves that discrimination negatively affects continuance commitment. The result $\left(\mathrm{R}^{2}=0.136, \mathrm{P}=0.0\right)$ suggests that when teachers experience any kind of discrimination, the result is a $13.6 \%$ decrease in the level of teachers' continuance commitment (See table 7).

Table 7. Correlation and Regression between Discrimination and Continuance Commitment

\begin{tabular}{lllll}
\hline Model & $\mathrm{R}$ & $\mathrm{R}^{2}$ & Adjusted $\mathrm{R}^{2}$ & SE of the estimate \\
\hline 1 & -.369 & .136 & .130 & .507 \\
\hline
\end{tabular}

c) The analysis results in a Pearson coefficient of 0.631 , and the value is significant $(\mathrm{P}=0.00)$, showing a significant effect for training on the level of continuous commitment. The result $\left(\mathrm{R}^{2}=0.399, \mathrm{P}=0.000\right)$ shows that if teachers are trained well, their level of continuance commitment increases by $39.9 \%$ (see table 8 ).

Table 8. Correlation and Regression between Training and Continuance Commitment

\begin{tabular}{lllll}
\hline Model & $\mathrm{r}$ & $\mathrm{R}^{2}$ & Adjusted $\mathrm{R}^{2}$ & SE of the estimate \\
\hline 1 & .631 & .399 & .395 & .423 \\
\hline
\end{tabular}

Findings 2: Both communication and training positively affect teachers' level of continuance commitment positively, whereas discrimination has a negative effect on it. Accordingly, hypothesis two is fully accepted. The results also show that communication $(0.402)$ has much more effect than training $(0.399)$ and discrimination $(0.136)$ on the level of continuance commitment.

\section{Hypothesis 3}

g) The analysis results in a Pearson coefficient of 0.620 , and the value is highly significant $(\mathrm{P}=0.0)$. This positive correlation coefficient implies that communication can positively affect teachers' normative commitment. Specifically, the result $\left(\mathrm{R}^{2}=0.384, \mathrm{P}=0.0\right)$ suggests when communication is well-employed, there is a $38.4 \%$ increase in teachers' feeling that they are in the right organization (See table 9).

Table 9. Correlation and Regression between Communication and Normative Commitment

\begin{tabular}{lllll}
\hline Model & $\mathrm{R}$ & $\mathrm{R}^{2}$ & Adjusted $\mathrm{R}^{2}$ & SE of the estimate \\
\hline 1 & .620 & .384 & .380 & .463
\end{tabular}

a) The analysis results in a Pearson coefficient of -0.295 , and the value is highly significant $(\mathrm{P}=0.0)$. This negative value of correlation coefficient implies that discrimination negatively affects the teachers' normative commitment. The result $\left(\mathrm{R}^{2}=0.087, \mathrm{P}=0.0\right)$ suggests that if teachers experience a kind of discrimination, their feeling of obligation towards their school decreases by $8.7 \%$ (see table 10 ).

Table 10. Correlation and Regression between Discrimination and Normative Commitment

\begin{tabular}{lllll}
\hline Model & $\mathrm{R}$ & $\mathrm{R}^{2}$ & Adjusted $^{2}$ & SE of the estimate \\
\hline 1 & -.295 & .087 & .081 & .564 \\
\hline
\end{tabular}

b) The analysis results in a Pearson coefficient of 0.530 , and the value is highly significant $(\mathrm{P}=0.0)$. This result shows a positive correlation between training and teachers' normative commitment. The result $\left(\mathrm{R}^{2}=0.281, \mathrm{P}=0.00\right)$ shows that 
even if training is well-created and managed, there is a chance of increasing teachers' level of normative commitment by $28.1 \%$ (See table 11 ).

Table 11. Correlation and Regression, between Training and Normative Commitment

\begin{tabular}{lllll}
\hline Model & $\mathrm{r}$ & $\mathrm{R}^{2}$ & Adjusted $\mathrm{R}^{2}$ & SE of the estimate \\
\hline 1 & .530 & .281 & .277 & .500 \\
\hline
\end{tabular}

Findings 3: Both communication and training positively affect teachers' normative commitment, whereas discrimination has a negative effect. Thus, the third hypothesis is accepted. The results show that communication (.384) has much more effect than training (0.281) and discrimination (0.087) on the level of normative commitment.

\section{Discussion and Conclusion}

This study has attempted to examine the relationship between culture diversity challenges (communication, discrimination and training) and organizational commitment approaches (affective, continuance and normative). In concordance with the study of Abidin et al. (2010), the results of the current study show a strong positive relationship between communication and organizational commitment approaches (affective, continuance and normative). In line with the study of (Alas \& Mousa, 2016) the results of this study affirm the importance of diversity training for enhancing organizational effectiveness. Moreover, the statistical results explore a positive relationship between training and organizational commitment approaches. Additionally, the statistical results of this study indicate a negative correlation between discrimination and organizational commitment approaches (affective, continuance and normative).

Training has emerged to be the most dominant variable in predicting teachers' affective commitment to their schools, whereas, communication tends to be the most influential factors in terms of both continuance and normative commitment.

As illustrated by Alas \& Mousa (2016), cultural diversity is viewed as a main challenge in today's schools. Along with other factors such as racial differences, gender, language and religion, absorbing cultural diversity needs to be included as part of the school's organizational strategy and/ or culture (Hite \& McDonald, 2006 and Alas \& Mousa, 2016). Managing teachers' cultural diversity allows schools to adjust to the socio-cultural shifts in the societies where they work in and then constitute policies, courses, initiatives, and practices that disseminate the soul of equality and tolerance. Accordingly, any poor planning and/ or execution for cultural diversity aspects may yield to many struggles that subsequently hinder teachers' level of organizational commitment.

Given the history of public schools in Egypt, the ministry of education and school administrations need to understand that cultural diversity management is no longer limited to management intervention, but it should be employed as a considerable, recognizable, and adoptable policy. Thus, promoting and maintaining cultural diversity practices such as inclusion, integration, solidarity, tolerance and equality are important for creating a productive work environment where teachers feel appreciated and often have a desire to continue their memberships in their schools.

This study may be subject to criticism for excluding moderating variables such as turnover values, organizational satisfaction, and organizational citizenship behaviors. However, such moderating variables may be considered in future research by the researcher and/or other scholars in the academic management field.

Given the importance of cultural diversity for future teacher organizational commitment, an investigation should be conducted to determine whether or not cultural diversity is involved in teachers' development initiatives (training, coaching, mentoring and etc.) and under which learning paradigm (a discrete course, a discussion woven throughout teachers' courses, or a stand-alone training). This may assist in identifying the extent to which school administrations may employ cultural diversity practices (tolerance, equality, solidarity and inclusion) in enhancing teachers' emotional feelings towards their schools and hence decreasing their intentions to leave. Moreover, applying the same research approach in another organizational setting (private sector and/ or non-profitable organizations) may assist in affirming or adding to the results of current research.

\section{References}

Abidin, S. N. S. Z., Muda, M. S., Hasan, F. A., \& Salleh, A. M. M. (2010). Organizational commitment in Malaysian public sector. IJMS, 17(1). http://www.ijms.uum.edu.my

Alas, R., \& Mousa, M. (2016). Cultural diversity and business schools' curricula: a case from Egypt. Problems and perspectives in management, 14(2), (cont.-1), 130-136.

Alas, R., \& Mousa, M. (2016). Organizational culture and workplace spirituality. International journal of emerging research in management and technology, 5(3).

Allen, N. J., \& Meyer, J. P. (2000). Construct validation in organizational behavior research: the case of organizational commitment. In Guftin, R.D and Helmes, E. Problems and solutions in Human Assessment: Honoring Douglas N. 
Jackson at Seventy, Kluwer, Norwell, MA, 285-314. http://dx.doi.org/10.1007/978-1-4615-4397-8_13

Allen, N., \& Meyer, J. (1990). The measurement and antecedents of affective, continuance and normative commitment to the organization. Journal of occupational Psychology, 63(1). http://dx.doi.org/10.1111/j.2044-8325.1990.tb00506.x

Alzaroo, S., \& Hunt, G. (2003). Education in the context of conflict and instability: the Palestinian case. Social policy and administration, 37(2), 165-180. http://dx.doi.org/10.1111/1467-9515.00332

Bauer, P. (2013). European-Mediterranean security and the Arab spring: changes and challenges. Democracy and security, 9. http://dx.doi.org/10.1080/17419166.2012.736299

Becker, H. (1960). Notes on the concept of commitment. American Journal of Sociology, 66(1). http://dx.doi.org/10.1086/222820

Bryant, S., Moshavi, D., \& Nguyen, T. (2007). A field study on organizational commitment, professional commitment and peer mentoring. Database for advances in information systems, 38(2). http://dx.doi.org/10.1145/1240616.1240622

Chang, E. (1999). Career commitment as a complex moderator of organizational commitment and turnover intention. Human relations, 43(10). http://dx.doi.org/10.1177/001872679905201002

Chang, E. (2002). Distributive Justice and organizational commitment revisited: moderation by layoff in the case of Korean employees. Human Resources Management, 4l(2). http://dx.doi.org/10.1002/hrm.10035

Clercq, D. D., \& Rius, I. B. (2007). Organizational commitment in Mexican small and medium- sized firms: the role of work status, organizational climate and entrepreneurial orientation. Journal of small business management, 45(4). http://dx.doi.org/10.1111/j.1540-627x.2007.00223.x

Devine, F., Baum, T., Hearns, N., \& Devine, A. (2007). Managing cultural diversity: opportunities and challenges for Northern Ireland hoteliers. International journal of contemporary hospitality, 29(2).

Dogra, N. (2001). The development and evaluation of a programme to teach cultural diversity to medical undergraduate students. Medical education, 35, 232-241. http://dx.doi.org/10.1046/j.1365-2923.2001.00734.x

Enriquez, V., Mc Bride, J., \& Paxton, L. (2001). Improving knowledge of strategic goals and the impact on organizational commitment: Health Marketing Quarterly, 18(3/4). http://dx.doi.org/10.1300/j026v18n03_09

Findler, L., Wind, L., \& Berak, M. (2007). The challenge of workforce management in a global society: Modeling the relationship between diversity, inclusion, organizational culture, and employee well- being, job satisfaction and organizational commitment. Administration in social work, 31(3). http://dx.doi.org/10.1300/J147v31n03_05

Gbadamosi, G. (2003). HRM and the commitment rhetoric: Challenges for Africa. Management Decision, 41, 274-280. http://dx.doi.org/10.1108/00251740310475218

Haim, A. B. (2007). Rethinking organizational commitment in relation to perceived organizational power and perceived employment alternatives. International journal of cross cultural management, 7(2).

Hargreaves, E. (2001). Profiles of educational assessment systems world-wide: Assessment in Egypt. Assessment in Education, 8(2), 247-260. http://dx.doi.org/10.1080/09695940124261

Harr, J. \& Spell, C. (2004). Programme knowledge and value of work. Family practice and organizational commitment. The international journal of human resources management, 15(6). http://dx.doi.org/10.1080/09585190410001677304

Heuberger, B., Gerber, D., \& Anderson, R. (2010). Strength through Cultural Diversity: Developing and Teaching a Diversity Course. College Teaching, 47(3), 107-113. http://dx.doi.org/10.1080/87567559909595797

Hofstede, G., \& Hofstede, G. J. (2005). Cultures and organizations: software of the mind. McGraw Hill.

Humphrey, N., Bartolo, P., Ale, P., Calleja, C., Hofsaess, T., Janikofa, V., Lous, M., Vilkiene, V., \& Westo, G. (2006). Understanding and Responding to diversity in the primary classroom: an international study. European Journal of Teacher Education, 29(3), 305-313. http://dx.doi.org/10.1080/02619760600795122

Kaur, J., \& Sharma, S. K. (2015). Measuring organizational commitment: scale validation for Indian financial services sector. The IUP Journal of organizational behavior, XIV 4.

King, E., Gulick, L., \& Avery, D. (2010). the divide between diversity training and diversity education: integrating best practices. Journal of management education, 34(6), 891-906. http://dx.doi.org/10.1177/1052562909348767

Kormanik, M., \& Rajan, H. (2010). implications for diversity in the HRD curriculum drawn from current organizational practices on addressing workforce diversity in management training. Advances in developing Human resources, 12(3), 367-384. http://dx.doi.org/10.1177/1523422310375033 
Li, Y., Ahlstrom, D., \& Ashkanasy, N. M. (2010). A multilevel model of affect and organizational commitment. Asia pacific journal of management, 27. http://dx.doi.org/10.1007/s10490-010-9193-9

Mahrous, A., \& Kortam, W. (2012). Students' evaluations and perceptions of learning within business schools in Egypt. Journal of Marketing for higher education, 22(1), 55-70. http://dx.doi.org/10.1080/08841241.2012.705794

Meyer, J., \& Allen, J. (1997). Commitment in the workplace- Theory research and application. Thousand oaks, CA: Sage Publications.

Misra, S., \& McMahon, G. (2006). Diversity in higher education: the three Rs. Journal of education of business, 40-43. http://dx.doi.org/10.3200/JOEB.82.1.40-43

Morrison, M., Lumby, J., \& Sood, K. (2006). Diversity and diversity management: Messages from recent research. Educational management administration and leadership, 34(3), 227-295. http://dx.doi.org/10.1177/1741143206065264

Mousa, M., \& Alas, R. (2016). Workplace spirituality and organizational commitment: A study on the public schools teachers in Menoufia (Egypt). African Journal of Business Management, 10(10).

Mowday, R. T., Porter, L. M., \& Steers, R. M. (1982). Employee organizational linkages: The psychology of commitment; absenteeism and turnover, New York: Academic Press.

OECD. ( 2008). Retrieved from: http://www.oecd.org/countries/egypt/40577424.pdf

Ogbonna, E., \& Harris, L. (2006). The dynamics of employee relationships in an ethnically diverse workforce. Human relations, 59(3), 379-407. http://dx.doi.org/10.1177/0018726706064181

Omar, K., Anuar, M. M., Majid, A. H. A., \& Johari, H. (2012). Organizational commitment and intention to leave among nurses: the mediating role of moral obligation. IJMS, 19(2). http://ijms.uum.edu.my/ .

Perry, R. (2004). The relationship of affective organizational commitment with supervisory trust. Review of public personnel administration, 24(2). http://dx.doi.org/10.1177/0734371X03262452

Pitts, D., \& Wise, L. (2010). Workforce Diversity in the new millennium: prospects for research. Review of public personnel administration, 30(1), 44-69. http://dx.doi.org/10.1177/0734371X09351823

Porter, L. W., Steer, R. M., Mowday, R., \& Boutin, P. V. (1974). Organizational commitment, job satisfaction, and turnover among psychiatric technicians. Journal of Applied Psychology, 59(2). http://dx.doi.org/10.1037/h0037335

Rajendran, M., \& Raduan, C. R. (2005). Antecedents and outcomes of organizational commitment among Malaysian engineers. American journal of applied science, 2(6).

Roberson, L., Kulik, C., \& Pepper, M. (2001). Designing effective diversity training: influence of group composition and trainee experience. Journal of organizational behavior, 22, 871-885. http://dx.doi.org/10.1002/job.117

Roberson, Q., \& Park, H. (2007). Examining the link between diversity and firm performance. Group and organization management, 32(5), 548-568. http://dx.doi.org/10.1177/1059601106291124

Sekaran, U. (2003). Research methods for business. A skill building approach (4th Ed.). United States of America: John Wiley and Sons.

Sharma, P., \& Sinha, V. (2015).The influence of occupational rank on organizational commitment of faculty members. Management, 20(2).

Stel, N. (2013). Governance and government in the Arab Hybridity: Reflections from Lebanon. Working paper 12. Maastricht School of Management.

Subeliani, D., \& Tsogas, G. (2005). Managing diversity in the Netherlands: a case study of Rabobank. International journal of human resources management, 16(5), 831-851. http://dx.doi.org/10.1080/09585190500083392

Vuuren, H., Westhuizen, P., \& Walt, V. (2012). The management of diversity in schools- A balancing act. International Journal of Education Development, 32, 155-162. http://dx.doi.org/10.1016/j.ijedudev.2010.11.005

Wentling, R., \& Rivas, N. (1999). Components of effective diversity training programmes. International journal of training and development, 3(3), 215-228. http://dx.doi.org/10.1111/1468-2419.00079

Zanoni, P., Janssens, M., Benschop, Y., \& Nkomo, S. (2009). Unpacking diversity, grasping inequality: rethinking difference through critical perspective: organization, 17(1), 9-29.

\section{Copyrights}

Copyright for this article is retained by the author(s), with first publication rights granted to the journal.

This is an open-access article distributed under the terms and conditions of the Creative Commons Attribution license (http://creativecommons.org/licenses/by/3.0/). 